\title{
Hans Peterson (1928 - 2021) - Forever in Our Hearts, Always in Our Thoughts
}

\author{
By Sabine Koch, David Shires, Diane Skiba, Marion Ball, Jan H. van Bemmel
}

With great sadness we received the message that Dr. Hans Peterson had passed away on January 27 th, 2021. For more than 40 years, he has been a leading figure in the international medical informatics community and his death means a great loss for medical informatics in his home country Sweden and internationally.

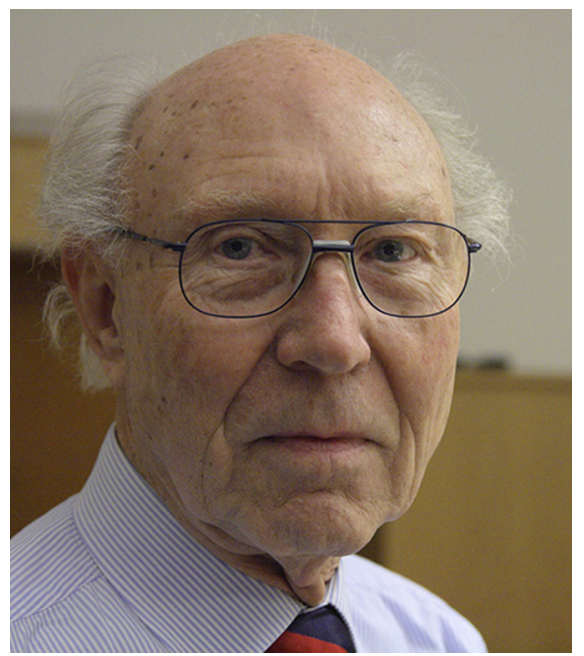

Hans Peterson was born in 1928 in Karlskoga, Sweden. After graduating in Medicine at Karolinska Institutet in Stockholm in 1958, he worked as an ophthalmologist at Karolinska University Hospital. In 1967 he received a $\mathrm{PhD}$ degree in Medical Sciences from Karolinska Institutet and became Associate Professor in Ophthalmology. In 1978, he was appointed Associate Professor in Medical Informatics at Karolinska Institutet. During his doctoral studies, he had worked with computerized patient records and was recruited as Head of a new Department of Medical Informatics at Stockholm County Council in 1971, where he coordinated the computerization of laboratories, and of the patient-related administration in health care centers and hospitals until 1990. During all these years he worked as ophthalmologist one day per week and perceived the experiences of seeing patients and clinical colleagues, while developing practical computer and information systems, as his most happy and fruitful professional experiences. From 1994 - 2000 he was responsible for a project about computerized care documentation at the Swedish Institute for Health Services Development (SPRI). The project was initiated by the Swedish Government and most health care providers in the country participated to put together the lessons learned after 35 years of experience working with computerized patient records. Parts of this history are summarized in his article in the 2006 IMIA Yearbook [1].

Hans was one of the first members of the Swedish Society of Medical Informatics (SFMI), and its President from 1980 - 1984. He actively supported the establishment of IMIA and the European Federation of Medical Informatics (EFMI). Having been a member of the organizing committee of the first MEDINFO 1974 in Stockholm, he became President of IMIA from 1983-1986 and was very active in the process of making IMIA an independent organization from the International Federation of Information Processing (IFIP) in 1986. He was further one of the founders and Vice-President of EFMI from 1976-1980. He was the head of the Swedish delegation to the European Standardization organization and expert consultant for the Swedish National Board of Health and Social Services in Health Informatics for many years, helping to create legislation for patient records and the creation of national information structures for health care.

Dr. Peterson was an Honorary Fellow of IMIA, an Honorary Fellow of EFMI and a Fellow of the American College of Medical Informatics (ACMI). In 2010 he received the IMIA Award of Excellence (now known as the François Grémy Award of Excellence) and he was elected to IMIA's Academy, the International Academy of Health Sciences Informatics (IAHSI), as part of the Inaugural Class of Fellows in 2017.

Dr. Peterson was also very instrumental in supporting the development of IMIA Working Group 8, now known as IMIA NI Special Interest Group, for which he was recognized as an honorary member of. In 1987, his wife Ulla Gerdin sponsored a Nursing Informatics Education Task Force conference in Stockholm, where he served as a member of the organizing committee and as one of the editors of the resulting publication. He was an internationally prominent and prolific author who had served as editor for textbooks on Communication Networks in Health Care and Human-Computer Communications in Health Care. He had also served on the Editorial Boards of a number of journals, including Methods of Information in Medicine, Medical Informatics, Lecture notes in Medical Informatics, and the Journal of Clinical Computing.

His achievements were numerous, but despite this he was a very humble person with a great sense of humor, eager to share his experiences with the next generations. He devoted a lot of time and energy into describing the history of informatics and arranged a series of interviews with the Swedish pioneers in medical informatics 
together with the Technical Museum in Stockholm [2]. As late as in 2015 he participated in the very first massive open online course (MOOC) on eHealth [3] to share the lessons learned from his professional life [4]. He wanted us to learn from the past, to avoid repeating the same mistakes, and to nurture international collaboration. To learn from each other and share experiences through international networks such as IMIA was what he cherished most.
Hans was a kind and gentle soul who always had a twinkle in his eye. Personally and professionally we do miss him dearly and our thoughts go to his wife Ulla and his family.

Thank you, Hans! You have left us with such great memories that will keep you alive in our hearts.

\section{References}

1. Peterson H. From Punched Cards to Computerized Patient Records: A Personal Journey. Yearb Med Inform 2006:180-6.

2. Dussauge I. Interview with Hans Peterson [in Swedish only]. https://www.tekniskamuseet.se/ wp-content/uploads/2017/08/47-hans-peterson. pdf [cited 2021 May 29].

3. Koch S, Hägglund M. Mutual learning and exchange of health informatics experiences from around the world - Evaluation of a Massive Open Online Course in eHealth. Stud Health Technol Inform 2017;245:753-7.

4. Koch S, Peterson H. Lessons learned from the history of Medical Informatics. Interview recording, February 2015. https://youtu.be/cLWK4egr9tE [cited 2021 May 29]. 